\title{
Management of End Stage Renal Disease-Bangladesh Perspective
}

\author{
Harun Ur Rashid*
}

Kidney Foundation Hospital and Research Institute, Dhaka, Bangladesh

\begin{abstract}
End stage renal disease (ESRD) is an important cause of morbidity and mortality throughout the world. The treatment of renal replacement therapy (RRT) for patients with ESRD is expensive. There is a direct relationship between per capita income and treatment of ESRD. Eighty five per cent of the world's population lives in low income or middleincome countries, where the mortality is highest in patients with chronic kidney disease.

The future perspective is not satisfactory for Bangladesh where treatment of ESRD is out of reach for majority of people. Effort should made for prevention and treatment of CKD at an initial stage of disease.
\end{abstract}

Keywords: Chronic kidney disease, cost of treatment, end stage renal disease, renal replacement therapy.

\section{INTRODUCTION}

There remains a major challenge to providing optimal treatment of End Stage renal disease (ESRD) world-wide. Early detection and prevention program will go a long way in mitigating the challenge.

There are approximately 2 million patients world-wide who regularly receive renal replacement therapy (RRT) in the form of dialysis. Of them, more than $80 \%$ are on Hemodialysis (HD) and $15 \%$ are on Peritoneal Dialysis (PD), mostly from developed nations. On the other hand, more than 1.5 million people die every year simply because they don't have access to any form of RRT and these patients are mostly from developing nations. The cost of RRT is enormous, even highly developed nations, cannot cope with it $[1,2]$.

\section{RENAL DISEASE IN BANGLADESH}

Data from hospital, urban and underprivileged population based studies suggest that there is a CKD prevalence of 16$18 \%$ in Bangladesh; of them, $11 \%$ belong to stage-III and above [3-5]. Data from hospital based studies and dialysis units suggest that chronic glomerulonephritis (proteinuria and bilaterally small kidneys) and interstitial nephropathy comprise $37 \%$ of causes of ESRD. Diabetic nephropathy constitutes $33 \%$ and hypertension $16 \%$. Prevalence of nondialysis ESRD is unknown. Data suggest that it could be 200-250 patients per million population per year [6].

RRT in ESRD patients is the less priority area in Bangladesh because of government policy on health. The priority areas are prevention of communicable disease, mother and child health and family planning. As a result, there are few government hospitals offering treatment of

*Address correspondence to this author at the Plot No. 5/2, Road No. 1, Section-2, Mirpur, Dhaka-1216, Bangladesh; Tel: 8055827, 8053786;

E-mail: rashid@bol-online.com
ESRD. Most of the RRT is offered by non-government hospitals, clinics and NGOs.

The first hemodialysis was done in Bangladesh in 1965 and regular dialysis was started since 1986.

There are now approximately 84 dialysis centers in the whole country. Of them, half of the dialysis centers are in the capital city of Dhaka. Other centers are spread in the six large cities of the country. If 200 patients per million population reach ESRD per year, there would be approximately 30,000 new patients per year. Presently available facilities can hardly accommodate only 900010,000 new patients (twice weekly dialysis); that means, $66 \%$ of patients have no access to HD (Fig. 1).

\section{COST OF DIALYSIS}

Eighty per cent of dialysis centers are profit oriented. Cost of single dialysis ranges from 3500-5000 taka per dialysis (US\$ 44-62.00) and only $20 \%$ are non - profit hospitals, both public and NGO based, where cost ranges from 1000-1500 taka per dialysis (US \$12-18.00)

\section{QUALITY OF HEMODIALYSIS}

There is no study regarding quality of life and prognosis of hemodialysis patients throughout the county except few teaching hospitals.

Data of ESRD patients were collected from 1000 patients from 20 centers all over the city in $2009-2010$. The data showed that mean age of patients on HD was $40 \pm 15$ years (range 16-68). Of them, 546 were males and 454 were females. Mean Hemoglobin was 8-10 gm/dl, erythropoietin was received by $39 \%$ patients and $66 \%$ were undergoing twice weekly dialysis.

Survival of ESRD patients on dialysis was estimated in one non -profit center which showed 1,3,5 years survival rates of $90 \%, 75 \%$ and $55 \%$ respectively (Fig. 2). 


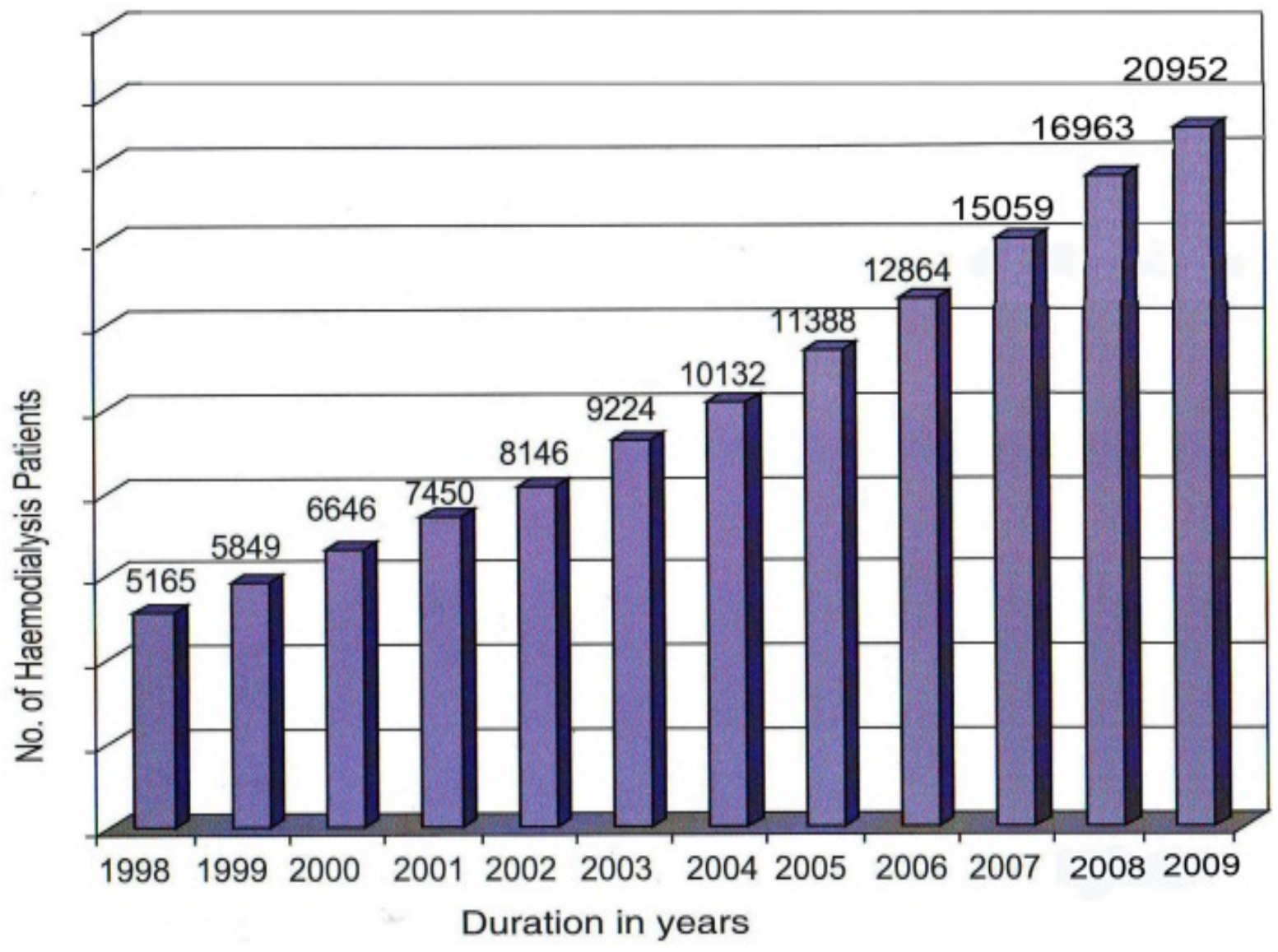

Fig. (1). Prevalence of Hemodialysis in Bangladesh.

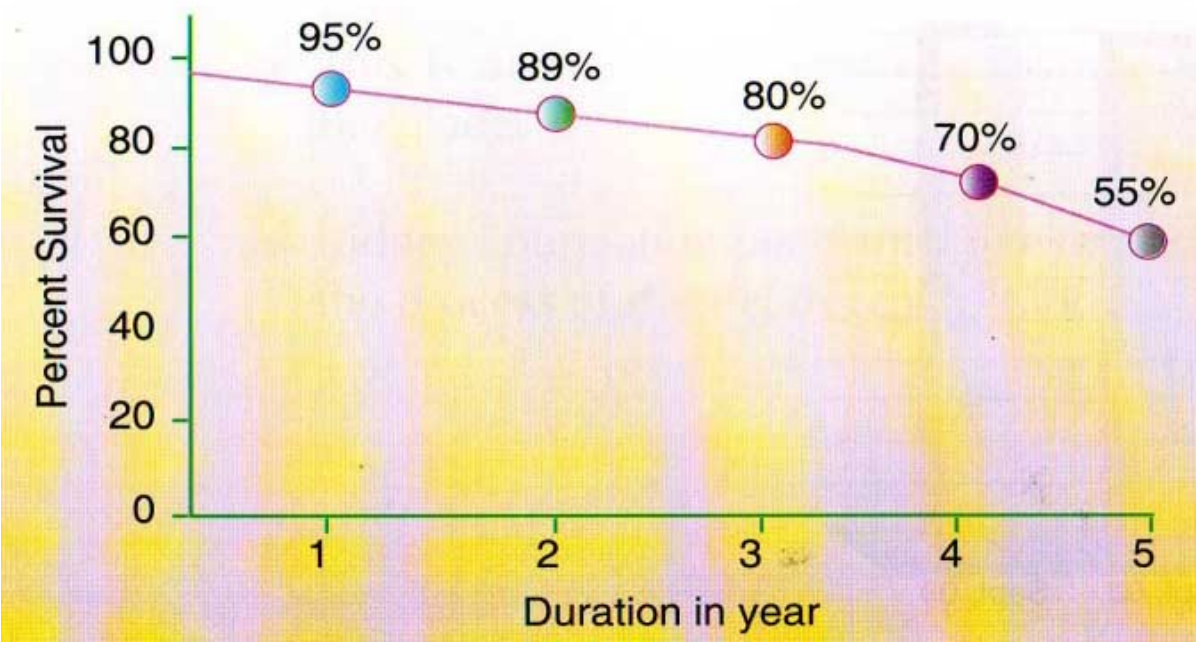

Fig. (2). Survival of hemodialysis in kidney foundation hospital $(\mathrm{n}=210)$.

\section{Continuous Ambulatory Peritoneal Dialysis (CAPD)}

Although PD was started in 1986, it is not yet a popular form of therapy in Bangladesh. There are now 10 centers offering PD services, but only two centers perform PD regularly. There are approximately 600 patients of CAPD since 2003 until 2012 (Fig. 3). The mean age of patients on CAPD is $56 \pm 16$ years. Major causes of ESRD of CAPD patients are Diabetic Nephropathy (75\%), chronic glomerulonephritis (20\%) and Hypertension (18\%). The main indications for PD are vascular access problem, hemodynamic instability, cardiovascular disease and older age. There has been a progressive improvement of survival and quality of life in PD patients since 2003 in Bangladesh. The incidence of peritonitis has decreased from one per14 patient months in 2003 to one per 34 patient months in 2010.

The main obstacle of PD in Bangladesh is physicians' attitude towards PD and cost of PD fluid. One PD fluid bag cost about 325 taka. (US\$ 4.00) and three exchange cost per 


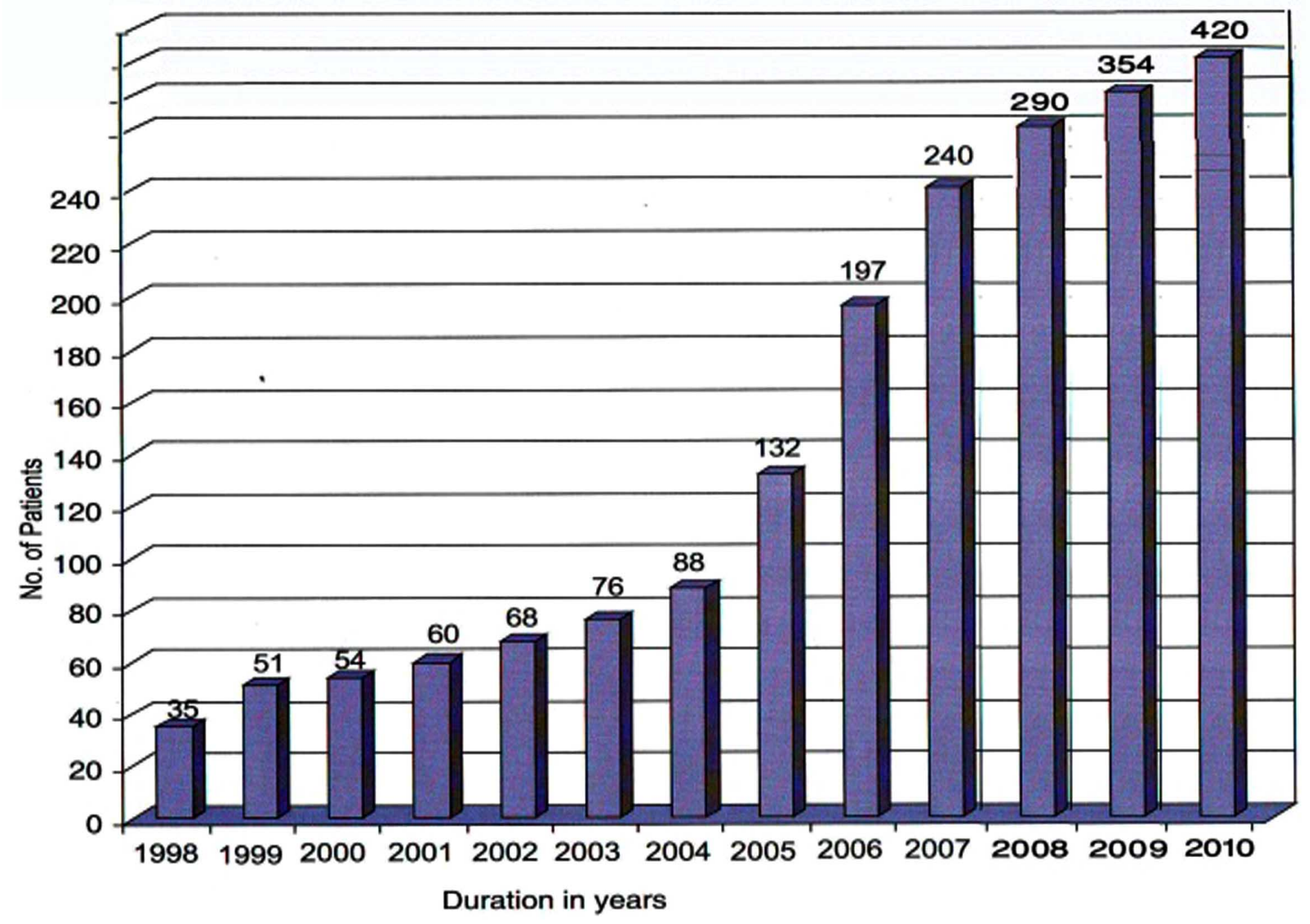

Fig. (3). Prevalence of CAPD in Bangladesh.

day is 1000 taka (US\$ 12.5), and this is equivalent to cost of HD in profitable hospitals.

However, PD can be a good alternative to HD in view of its inherent advantages.

\section{RENAL TRANSPLANTATION}

Although renal transplantation is an essential, viable and cost effective therapy, donor shortage precludes renal transplantation as a first line of treatment for patients with ESRD

Although, $1^{\text {st }}$ renal transplantation was done in October 1981 in Bangladesh, regular transplantation was started only in1988. Until 2004, there was only one center performing renal transplantation. Now there are eight transplant centers in the whole country. Only live related transplantation is being performed in Bangladesh. So far, about1079 renal transplants have been done (Fig. 4). The mean age of recipients is $34 \pm 15$ years. Donors are close relatives. Majority of the donors are parents $(61 \%)$, followed by siblings $(34 \%)$, spouse $(3 \%)$, and $2^{\text {nd }}$ degree relatives $(2.4 \%)$ The immunosuppressive drugs used are prednisolone, azathioprine and cyclosporine. After 2006, azathioprine was replaced by mycophenolate mofetil and cyclosporine by tacrolimus.

The major complications in our patients are infections and acute rejection. Tuberculosis is also very common after transplantation (12\%).

One, three and five year survival rates are 95\%, 88\%, $75 \%$ respectively. Efforts are now being made to start deceased donor transplantation; but, lack of sensitization among the public and patients, inadequate facilities and training to maintain brain dead persons and negative attitude of transplant surgeons have made it difficult to start deceased donor transplantation in Bangladesh.

\section{DISCUSSION}

There is a direct relationship between gross national product (GNP) and RRT. RRT is so costly that there is less probability of the vast majority of developing world population to take advantage of it [7].

As of now, the future of renal transplant scenario remains gloomy in countries like Bangladesh. Hence, their emphasis 


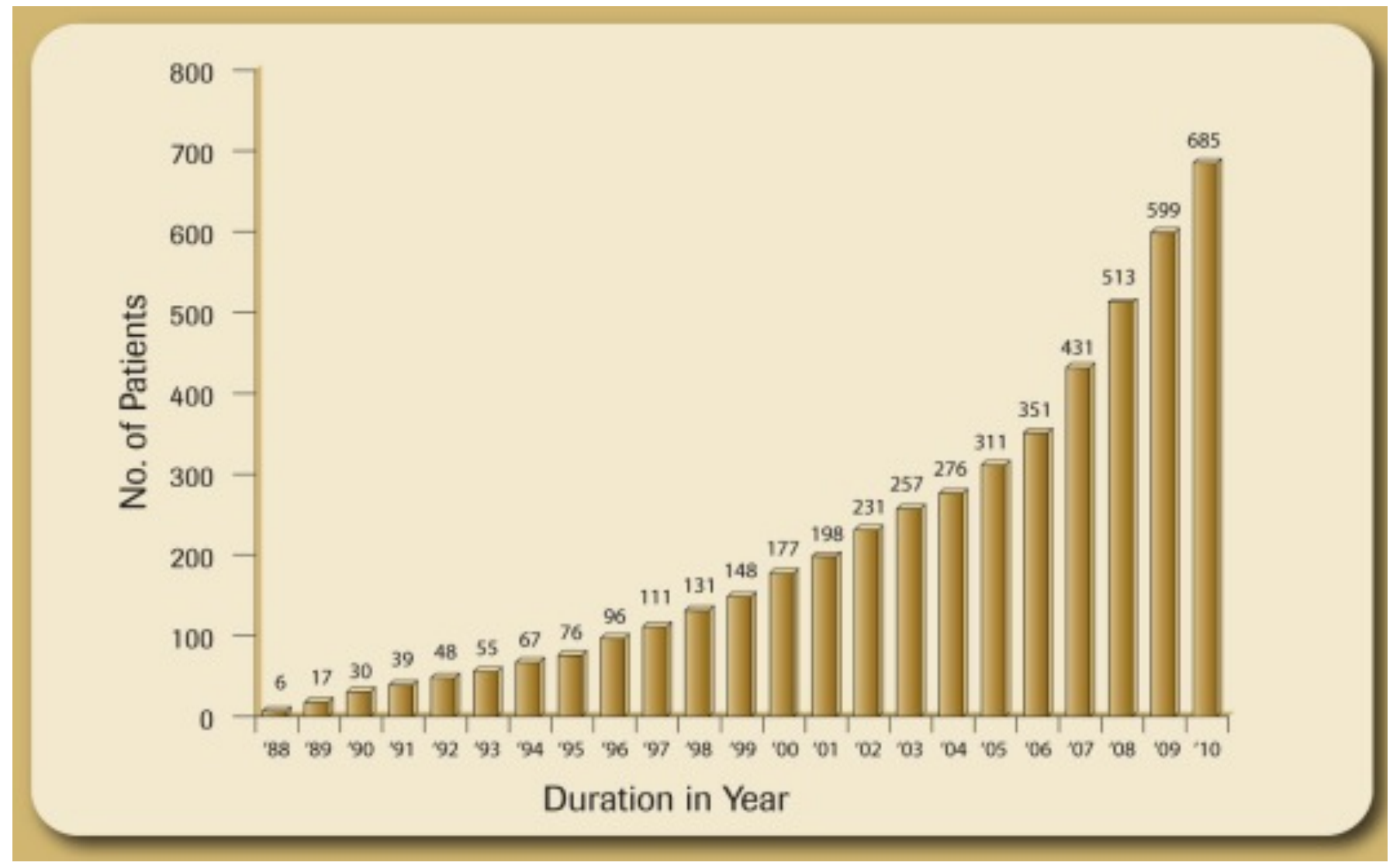

Fig. (4). Prevalence of Renal Transplant Patients in Bangladesh (1988-2010).

should shift from RRT to more cost effective preventive strategies.

However, whatever preventive measures we take, a significant number of patients will reach ESRD every year.

We therefore need to create more space for treatment of ESRD patients either by dialysis or transplantation. Although renal transplantation is the best form of treatment of patients with ESRD there is limitation of treatment due to scarcity of donors [8].

As a result, patients have to rely on either HD or PD. Both the modalities have similar survival both in short and long term basis. PD has certain advantages - home based therapy, no need for expensive machineries and freedom from serious infections like hepatitis B and C $[9,10]$ Quality of life of PD patients is as good as that of HD patients [11].

However there is confusion regarding the cost of therapy. There are several published articles which compare the cost of PD with that of HD. Just et al., in 2008, analysed the ratio of HD to PD costs in various developing and developed countries. The article concluded that HD is more expensive modality than PD in developed countries. There is lack of data regarding the cost in developing countries.

In view of several advantages of PD over HD, it would be appropriate for Bangladesh to expand the facility of PD. However, lack of awareness among physicians, and patients, physicians' attitude towards hemodialysis in profit making hospitals, it is difficult to introduce PD in remote places in Bangladesh.
Whatever form of RRT is chosen for our patients, the main issue is high cost of treatment. The cost of HD at private hospitals are between US\$ $6000.00-8000.00$ for 1 year. It erythropoietin is used the cost would be about US\$ 1000.00 . This cost is out of reach for more than $(80 \%)$ of ESRD patients. More than $80 \%$ of patients cannot afford dialysis in profitable centers. The cost of treatment in public hospitals and centers run by NGO and kidney foundation is $50-70 \%$ cheaper than profitable dialysis centers, As a result, patients are overcrowded in the non profit centers. Many patients start dialysis in profitable centers, continue for 6 months to 1 year and then stop treatment due to financial reason.

Renal transplantation is cheaper than HD or PD, and quality of life is much superior. However, donor scarcity remains a major issue. Unless we start deceased donor transplantation, it would be difficult to increase the number of transplantation in this country.

All efforts should therefore be made to preserve renal function in patients with CKD and priority is to be given for early diagnosis and treatment. Increasing awareness of kidney disease among the population and physicians could result in early detection and treatment of the disease in the early stage and can prevent onset of CKD [12].

\section{CONFLICT OF INTEREST}

The author confirms that this article content has no conflict of interest. 


\section{ACKNOWLEDGEMENTS}

Declared none.

\section{REFERENCES}

[1] Scheppati A, Peirco N, Remuzza G. Preventing end stage renal disease: the potential impact of screening and intervention in developing countries. Nephrol Dial Transplant 2003; 18: 858-9.

[2] US Renal Data System. USRDS 2012. Annual data report. Atlas of chronic kidney disease and end stage renal disease in the United States. Bethesda, MD: National Institute Health, National Institute of Diabetes and Digestive and Kidney Disease 2012.

[3] Alam KS, Huda MN, Rashid HU, Saha M. Prevalence of diabetes mellitus, hypertension, proteinuria and association of these risk factors with estimated glomerular filtration rate (eGFR) in adult disadvantaged population. Bangladesh Renal J 2010; 29(1): 1-6.

[4] Faroque MO, Rashid HU, Rahman MH, Alam MR, Islam S. Prevalence of diabetes mellitus, hypertension and proteinuria in a rural area of Bangladesh. Bangladesh Renal J 2010; 29(1): 7-11.
[5] Hadiuzzaman KBM, Rahaman MH, Alam MR, et al. Prevalence of diabetes mellitus and hypertension in health service providers. Bangladesh Renal J 2010; 29(1): 12-5.

[6] Rashid HU. Kidney Foundation Year Book 2012; 9: 28-31.

[7] Barsoum R. Chronic kidney disease in the developing world. N Engl J Med 2006; 354: 997-9.

[8] Davis CL, Delmonico FL. Living donor kidney transplantation: a review of the current practices for the live donor. J Am Soc Nephrol 2005; 16: 2098-110.

[9] Nayak KS, Prabhu MV, Siroj, KA, Subhramanyan SV, Sridhar G. Peritoneal dialysis in developing countries. Contriub Nephrol 2009; 163: 270-7.

[10] Li PK, lee SL, Leung CB, et al. Increased utilization of peritoneal dialysis to cope with mounting demand for renal replacement therapy-perspective from Asian countries. Perit Dial Int 2007; 27 (2): S59-61.

[11] Just PM, Riella MC, Tschosik EA, Noe LL, Bhattacharyya SK, de Charro F. Economic evaluation of dialysis treatment modalities. Health Policy 2008; 86: 163-80.

[12] Levey AS, Atkins R, Carsh EP, et al. Chronic kidney disease as a global public health problem: approaches and initiatives- a position statement from kidney disease improving global outcomes. Kidney Intern 2007; 72: 247-59.

(C) Harun Ur Rashid; Licensee Bentham Open.

This is an open access article licensed under the terms of the Creative Commons Attribution Non-Commercial License (http://creativecommons.org/licenses/by-nc/3.0/) which permits unrestricted, non-commercial use, distribution and reproduction in any medium, provided the work is properly cited. 